\title{
Axillary Irradiation as an Imperative Alternative to Axillary Dissection in Clinically Lymph Node-Negative but Sentinel Node-Positive Breast Cancer Patients?
}

\author{
Mirko Nitsche $^{\mathrm{a}}$ Robert Hermann ${ }^{\mathrm{b}}$ \\ aZentrum für Strahlentherapie und Radioonkologie, Ärztehaus am DIAKO, Bremen, Germany \\ 'Zentrum für Strahlentherapie und Radioonkologie, Ärztehaus an der Ammerlandklinik, Westerstede,
}

\section{Keywords}

Adjuvant treatment - Breast cancer .

Curative radiotherapy - Sentinel lymph node

\section{Summary}

At the moment, positive sentinel lymph node dissection (SLND) of the axilla is followed by axillary lymph node dissection (ALND) as standard of care. Recent data proves that omitting ALND after positive SLND in clinically lymph node-negative early stage breast cancer patients is feasible with low recurrence rates. The well known effect of radiotherapy to destroy occult tumor cells highly contributes to these results as a large extent of level I and II lymph nodes are unavoidably included in standard tangential radiation treatment fields. Reviewing the up to date published data on axillary lymph node treatment with radiotherapy, we hypothesize that full dosage coverage of level I and II of the axilla in early stage breast cancer will improve outcome and should be further evaluated.

\section{Introduction}

Axillary lymph node dissection (ALND) is standard of care in patients with breast cancer showing positive nodes in sentinel lymph node dissection (SLND). Axillary irradiation (AI) is not routinely applied but often recommended in current guidelines for specific situations such as incomplete dissection of the axilla $(<10)$ or no dissection at all. Discussions about

\author{
Schlüsselwörter \\ Adjuvante Behandlung · Mammakarzinom . \\ Kurative Radiotherapie - Wächterlymphknoten
}

\section{Zusammenfassung}

Der aktuelle Therapiestandard beim Vorliegen eines positiven Wächterlymphknotens ist die Durchführung einer kompletten Axilladissektion. Neuere Studien zeigen aber, dass bei klinisch negativer Axilla und positivem Wächterlymphknoten auf eine Axilladissektion bei niedriger lokaler Rezidivrate verzichtet werden kann. Der bekannte Effekt, dass durch Radiotherapie okkulte Tumorzellen zerstört werden, hat mit Sicherheit zu den Ergebnissen beigetragen, wird doch ein großer Anteil von Level-I/II-Lymphknoten bei der standardmäßigen tangentialen Radiotherapie der Mamma durch die Einstrahlungsfelder erfasst. Nach Zusammenschau der bisher publizierten Daten zur Radiotherapie der axillären Lymphknoten stellen wir die Hypothese auf, dass eine volle Dosisabdeckung der Level-I- und -II-Lymphknoten die Ergebnisse beim frühen Mammakarzinom weiter verbessern kann. Dies sollte in klinischen Studien weiter evaluiert werden.

further indications for AI were followed up by several studies demonstrating an overall survival advantage for postoperative radiotherapy including the supraclavicular, parasternal and axillary lymph node regions [1-3]. In these studies, AI was used successfully for many years in addition to axillary node sampling (ANS) or ALND [4, 5]. However, the value of postoperative AI has not yet been proven by prospective randomized trials. With commonly used techniques of tangential

\section{KARGER \\ Fax +497614520714 \\ Information@Karger.de}

www.karger.com (c) 2011 S. Karger GmbH, Freiburg

$1661-3791 / 11 / 0065-0353 \$ 38.00 / 0$

Accessible online at:

www.karger.com/brc
Dr. med. Mirko Nitsche

Facharzt für Strahlentherapie und Radioonkologie

Zentrum für Strahlentherapie und Radioonkologie, Ärztehaus am DIAKO

Gröpelinger Heerstraße 406-408, 28239 Bremen, Germany

Tel. +49 421 610266-66, Fax -76

nitsche@strahlentherapie-bremen.com,www.strahlentherapie-bremen.com 
breast irradiation, axillary lymph node areas of levels I and II are partly enclosed in the radiation field, whereas in planned AI, levels I-III are completely included. In this review, we present the evidence for AI dependent on the type of axillary surgery, the pathological results, and the irradiation technique (tangential whole breast radiotherapy versus full AI).

\section{Impact of Tangential Whole Breast Radiotherapy without Al on Early Stage Breast Cancer with Clinically Negative Lymph Nodes}

The American College of Surgeons Oncology Group Z0011 trial revived the attention of the scientific community for different options of local treatment of the axilla in early breast cancer. Survival of patients with clinically invasive T1/T2 breast cancer, no palpable adenopathy, and 1-2 histologically positive sentinel lymph nodes (SLN) was analyzed with regard to the impact of complete ALND. All 891 patients underwent lumpectomy and adjuvant tangential whole breast radiotherapy. Patients with SLN metastases were randomized to undergo ALND or no further axillary treatment. The 5-year overall survival (OS) rate was $91.8 \%$ with ALND and 92.5\% with SLND alone and the disease-free survival (DFS) rate was 82.2 vs. $83.9 \%$, respectively. The locoregional recurrence rate was $1.6 \%$ in the SLND-alone group and $3.1 \%$ in the ALND group at 5 years. Thus, at a median follow-up time of 6.3 years, there were no statistically significant differences in local recurrence $(p=0.11)$ or regional recurrence $(p=0.45)$ between the 2 groups [6]. The interpretation of these data emphasizes the importance of adjuvant treatment in this setting. Chemotherapy was administered to approximately $58 \%$ of patients in both treatment arms. Its effect, particularly in the neoadjuvant setting with its proven nodal downstaging, is clearly demonstrated. Adjuvant treatment of all patients in the study included ipsilateral whole breast irradiation, unintentionally delivering varying doses to a substantial part of the level I and II lymph node areas. This may contribute to the study results. Of note, the study was closed early before recruiting the initially planned patient number. It is hypothesized that with tangential breast radiotherapy, occult axillary nodal metastases are partially sterilized thus achieving low nodal failure rates. Recent data from Wernicke et al. [7] report a 10-year follow-up of treatment outcomes in early stage breast cancer (AJCC I-II) and clinically negative axillary nodes. 265 patients were treated with tangential whole breast radiotherapy without an additional axillary field after lumpectomy and either SLND or ALND. The incidence of axillary failure and supraclavicular failure in both cohorts was $0 \%$. The 10-year progression-free survival in the SLND cohort and the ALND cohort was 88.2 and $85.7 \%$, respectively. Chronic lymphedema occurred in $4.6 \%$ in the SLND cohort and in $34.8 \%$ in the ALND cohort. The authors concluded that in patients with negative axillary nodal status such treatment provides encouraging long-term cure rates with low morbidity in contrast to those associated with ALND or addition of an axillary radiotherapy field [7]. Wong et al. [8] evaluated 92 patients with clinical stage I or II (AJCC I-II) invasive breast cancer and clinically negative axillary lymph nodes. Patients underwent breast-conserving surgery and adjuvant radiotherapy with whole breast tangential fields without ALND, SLND, or AI. No isolated axillary or supraclavicular regional failures were detected during follow-up (50 months). 2 patients developed a recurrence in the ipsilateral breast, and 7 patients developed distant metastases, whereupon 5 patients received adjuvant chemotherapy. Hoskin et al. [9] described 94 patients with clinically negative axillary nodes, who did not undergo axillary surgery or specific AI. With a median followup time of 35 months for surviving patients, 5\% developed axillary failure. Halverson et al. [10] found that none of their 21 patients with a median follow-up time of 51 months developed axillary failure after tangential radiotherapy without dissection. Kuznetsova et al. [11] described a series of 36 patients in whom ALND was omitted. 18 patients were treated with tangential fields only; the others received specific nodal radiotherapy. At a median follow-up of 60 months, no regional nodal failures were identified in either group. In a systemic review of Van Wely et al. [12], a total of 23,357 SLN-negative patients were investigated. 127 patients with axillary recurrence were identified, of whom 73 had whole breast radiotherapy as part of their initial treatment. The meta-analysis showed that even after negative SLNB, adjuvant external beam radiotherapy was associated with a significantly lower recurrence rate $(\mathrm{p}<0.0001)$, providing a strong indication for the effectiveness of tangential whole breast radiotherapy.

\section{Impact of Tangential Whole Breast Radiotherapy and Additional Al on Early Stage Breast Cancer with Clinically Negative Lymph Nodes}

In a prospective randomized trial, Louis-Sylvestre et al. [13] studied 658 patients $(<70$ years of age) with invasive carcinoma measuring less than $3 \mathrm{~cm}$, no clinically involved axillary lymph nodes, and no metastatic disease. The patients were treated with wide local excision and were randomized to receive either ALND or AI. The latter group received irradiation to the breast and to the axilla as well as to the internal mammary nodes. After ALND, patients with positive lymph nodes received irradiation to the internal mammary and supraclavicular lymph nodes. Patients without positive lymph nodes received radiotherapy also to the internal mammary lymph nodes if the tumor was located in the central or medial part of the breast. In the ALND group, 19 patients received CMF chemotherapy (cyclophosphamide, methotrexate, 5-fluorouracil) compared to 9 patients in the AI group, and both groups received adjuvant hormonal therapy according to menopausal status. At 10 and 15 years, survival rates were 
similar in both groups with 73.8 and $75.5 \%$, respectively. The axillary recurrence rate was $1 \%$ in the ALND group and $3 \%$ in the AI group $(\mathrm{p}=0.04)$. The results of this study are comparable to those of the ACSO Z0011 trial with a locoregional recurrence rate of $1.6 \%$ in the SLND-alone group and 3.1\% in the ALND group. This evidence is strengthened by a case control study from Spruit et al. [14] with 180 women $>50$ years of age and a clinically uninvolved axilla with T1/2 cN0 breast cancer in which AI was given instead of ALND. With a median follow-up of 7.2 years, the regional relapse rates were $1.1 \%$ in the irradiation group vs. $1.5 \%$ in the ALND group. OS was similar in both groups, and DFS was significantly better in the irradiation group. A large randomized Italian study also reported good results with regard to local failure and DFS in a comparable setup: 435 women with early stage breast cancer were either treated without axillary therapy or with AI after breast-conserving surgery. The results showed no difference between the 2 study arms with a 5-year DFS of $96 \%$. Axillary recurrences were $1.5 \%$ in the no axillary treatment group versus $0.5 \%$ in the AI group after a median follow-up of 63 month [15]. A prospective study by Wazer et al. [16] investigated 73 women aged $>65$ years with early stage breast cancer (AJCC I-II) with clinically negative axillary lymph nodes. Tumor excision as well as whole breast and regional lymph node irradiation (supraclavicular and axillary) were performed followed by adjuvant antihormonal treatment. The local and regional lymph node control rates were 92.5 and $100 \%$, respectively. Another study with the same inclusion criteria but retrospective design investigated 105 patients (mean age 64 years). No isolated axillary lymph node recurrence was observed. In 2 patients, axillary recurrences were accompanied by distant metastasis. The 5-year OS and DFS were 83 and $82 \%$, respectively [17].

\section{Impact of Tangential Whole Breast Radiotherapy and Additional Al on Early Stage Breast Cancer with Positive Axillary Lymph Nodes after ANS (<5) or Limited ALND}

Although axillary recurrences in patients treated with lumpectomy, ALND, and tangential breast radiation therapy is low, in $4-7 \%$ of patients with negative SLNs the remaining axillary lymph nodes may harbor occult malignant cells [18]. The incidence of recurrence might be even higher if 5 or less lymph nodes are recovered, or after positive ANS without complete ALND [19-21]. Forrest et al. [22] reported on 417 patients randomized for mastectomy followed by ANS (4nodes) or full axillary clearance. AI was given to patients with histological involvement of sampled nodes and no further axillary surgery. The axillary relapse rates were $3.0 \%$ in the axillary clearance group vs. $5.4 \%$ in the group with positive nodes on ANS followed by AI [22]. A retrospective review was carried out in Birmingham in 2008 to assess the outcome and morbidity of ANS with radiotherapy. Patients received 4-node ANS and were referred for AI when nodes were positive. There were 11/331 (3\%) lymph node recurrences after ANS + AI compared to $3 / 50(6 \%)$ in the group of patients treated with complete ALND. The rate of clinically relevant lymphedema at 5 years was significantly higher in the ALND group compared to the ANS group with 5 vs. $18 \%$, respectively $(p=0.01)$ [23]. Galper et al. [21] evaluated the risk of regional nodal failure in patients with clinically node-negative stage I or II invasive breast cancer, treated with either no dissection or a limited dissection defined as removal of 5 nodes or less followed by AI. Only 3 of 42 patients (7\%) with pathologically involved nodes had a local recurrence as first site of failure. A retrospective study was undertaken by Fodor et al. [19] to identify patients who benefit from adjuvant radiation therapy of the axilla and supraclavicular fossa. After ALND and either mastectomy or breast-conserving surgery, 712 patients received regional nodal irradiation (RNI) with $50 \mathrm{~Gy}$. In N1 patients with 5 or less retrieved nodes, the rate of axillary failure was $8.3 \%$ without RNI vs. $0 \%$ with RNI $(\mathrm{p}=0.2340)$.

\section{Impact of Tangential Whole Breast Radiotherapy without Additional Al on Early Stage Breast Cancer with Clinically Negative Lymph Nodes and with Sentinel Node Micrometastases}

One prospective study with 234 early stage breast cancer patients stage T1-2 N0 M0 $\leq 3 \mathrm{~cm}$ analyzed the outcome after detection of SLN micrometastases and omission of ALND. SLN micrometastases were detected in 12\% (27/224) of all patients. No difference was found after 77 month for OS and locoregional axillary and distant DFS in comparison to SLNnegative patients [24]. Guenther et al. [25] also focused on SNL micrometastases or isolated keratin-positive cells and the value of additionally ALND. 46 women were investigated having SLN metastases and no ALND for different reasons. No axillary recurrences were seen during follow up (4-61 month). Axillary, internal mammary, and supraclavicular radiation fields were not used with the exception of a single patient who received irradiation to an additional supraclavicular field.

\section{Ongoing Studies}

The phase 3 study AMAROS ('The aftermapping of the axilla: Radiotherapy or Surgery?'; EORTC 10981-22023) compared patients with early stage breast cancer and a positive SLN undergoing either ALND or AI. This study stopped recruiting in 2010, and the final analysis is awaited [26]. 


\section{Discussion}

The presented data show that AI is very effective in preventing axillary recurrences. A rate of $1-3 \%$ axillary recurrences in clinically lymph node-negative early stage breast cancer patients can be achieved, thus defining radiotherapy as an alternative to ALND [20]. After ANS with less than 5 resected axillary lymph nodes or limited ALND, radiotherapy as adjuvant treatment in cases where ALND is not completed is an excellent treatment option. The outcome with tangential whole breast radiotherapy and additional AI on early stage breast cancer with clinically negative lymph nodes also provides a firm basis for this being a possible alternative treatment option. If we focus on the impact of tangential whole breast radiotherapy only in early stage breast cancer with clinically negative axillary lymph nodes, several studies prove a low incidence of axillary recurrences compared to either SLND, ALND, or no axillary treatment at all. Furthermore, recent studies show that knowledge of further nodal status beyond SLN biopsy (SNB) does not significantly influence the decision for adjuvant systemic treatment, which is mostly based on tumor characteristics and SNB status alone [26]. The morbidity seen after ALND implies a risk of lymph edema and decreased arm and shoulder function in $5-35 \%$ of patients. Its severity depended on the extent of the dissection [4, 5, 27-29]. Only in limited axillary surgery morbidity seems to be as low as in AI [30, 31]. Uncommon side effects of AI include brachial plexopathy and radiation pneumonitis, and with technology in the field of radiooncology emerges rapidly providing favorable dose distributions and precise dose application, the rate of severe side effects is still declining [8]. The American College of Surgeons Oncology Group Z0011 trial excluded patients with 3 or more involved axillary lymph nodes and randomized patients with SLN metastases to undergo ALND or no further axillary treatment after positive SLND. ALND was defined as anatomic level I and II dissection with at least 10 nodes removed [6]. Standard whole breast tangential radiotherapy unavoidably includes a large part of level I and II due to technical reasons, whereas in full AI, levels I-III are intentionally and completely included. Referring to the data of Veronesi et al. [18], 4-7\% of patients with negative SLN harbor occult metastases in the remaining axillary nodes, again emphasizing the effect of radiotherapy on local nodal control. In both treatment cohorts in the study by Wernicke et al. [7] with 265 node-negative patients receiving either full ALND or SLND only and each treated with adjuvant whole breast tangential radiotherapy, the incidence of axillary recurrence was $0 \%$ after 10 years of follow-up. The study of Wong et al. [8] investigated adjuvant radiotherapy with whole breast tangential fields without ALND, SLND, or AI in 92 patients. This retrospective study, applying radiation techniques available in the period of 1988-1993, used conventional tangential fields encompassing the lower echelon axillary nodes, mostly of level I. In these studies, the effect of preventing local recurrence was reached by destroying occult tumor foci by inadvertent coverage of a large portion of the axilla. 2 studies investigated the dosage coverage of level I and II axillary lymph nodes with standard tangential field radiotherapy. One showed that the $95 \%$ isodose encompassed only an average of $55 \%$ of axillary level I-II lymph nodes. The other study reported a mean total dose in the volume of interest of lower than $40 \mathrm{~Gy}$ in all but $1(1 / 15)$ patient. The authors concluded that significant modifications in treatment planning for complete coverage of levels I-II are necessary as
'Standard tangential fields'
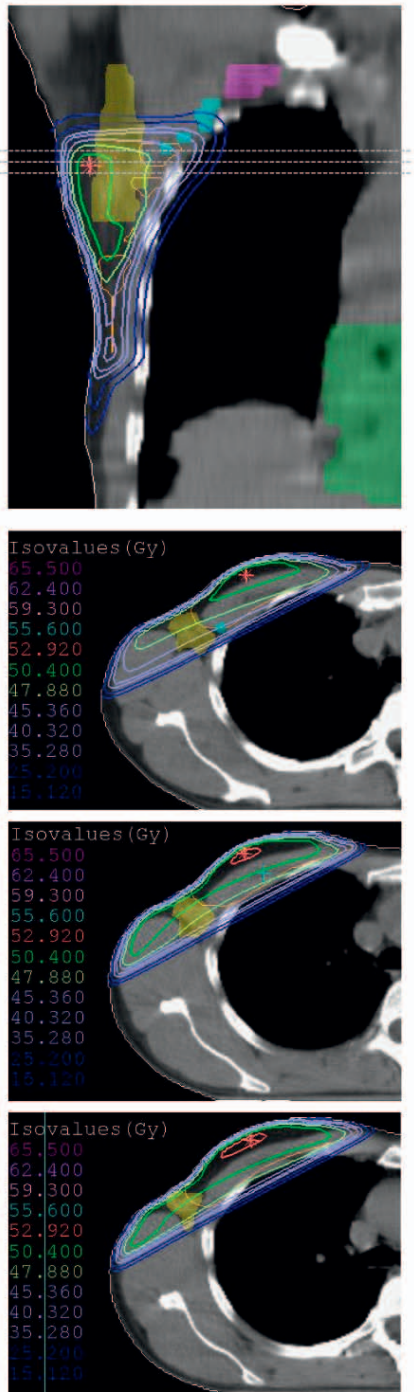

'Tangential fields with irradiation of axillary + supraclavicular lymph nodes'

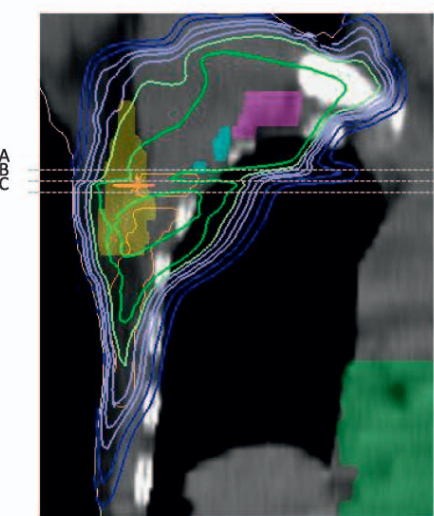

A
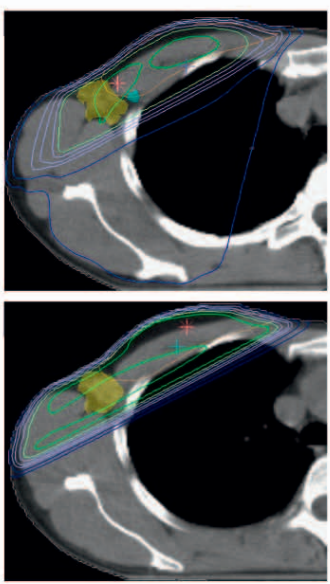

C

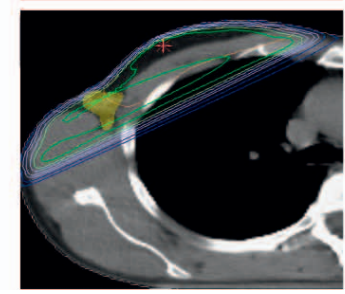

Fig. 1. Example for involvement of axillary lymph node regions in tangential breast radiotherapy: yellow = level I axillary lymph nodes, light blue $=$ level II, purple = level III. Isodoses are given in each picture of the left column. On the left side, 1 coronal and 3 transverse views of a standard tangential breast irradiation plan are presented (note the high amount of level I and II lymph node regions affected by irradiation). On the right side, a corresponding plan is shown specifically planned to irradiate the axillary and supraclavicular lymph node regions (half beam technique). 
the therapeutic dose is not delivered adequately [32, 33]. One should not dismiss the results of these studies, as the inadequate dosage coverage is explained by the purpose of the standard tangential field technique that was implemented to simply irradiate the breast tissue. Dose delivery to the level I-II anatomical lymph node region is a mere 'side effect' of the treatment. In full AI, all 3 lymph node areas are in the treatment fields with adequate target doses, hence the good results in axillary local control with tangential whole breast radiotherapy and additional AI in early stage breast cancer with clinically negative lymph nodes have a strong (fig. 1). Today, in the field of radiation oncology technology, numerous innovations in dose application and delivery are becoming available, such as three-dimensional computed tomography (3D-CT) planning with state of the art beam calculation algorithm including image fusion modalities to better define the target. The knowledge of anatomical boundaries of regional lymph nodes in treatment positioning is established to optimize conformal radiotherapy [34]. Furthermore, intensity modulated radiotherapy (IMRT), image-guided radiotherapy (IGRT), and volumetric modulated arc therapy (VMAT) upgrade the quality and precision of treatment delivery in radio- therapy. Hence, it has become possible to irradiate breast tissue and specific lymph node regions precisely at once, and this shift in technology will affect future study results.

In summary, irradiation of axillary lymph nodes is highly effective in controlling microscopic disease with equal efficacy and less morbidity than surgical procedures. Most recent data suggest that radiotherapy might have an impact on the prevention of further metastatic disease, which has never been shown for any surgical procedure. Thus, it can be hypothesized that, provided lymph node treatment impacts on outcome, radiotherapy may be the better treatment compared to surgery. Furthermore, improved dose coverage of level I-II lymph node areas in tangential breast radiotherapy may even further lower the rate of axillary recurrences in patients with positive SNL without ALND and clinically negative lymph nodes in early stage breast cancer.

\section{Disclosure Statement}

The authors declare that there is no actual or potential conflict of interest in relation to this article.

\section{References}

1 Overgaard M, Jensen MB, Overgaard J, Hansen PS, Rose C, Andersson M, Kamby C, Kjaer M, Gadeberg CC, Rasmussen BB, Blichert-Toft M, Mouridsen HT: Postoperative radiotherapy in high-risk postmenopausal breast-cancer patients given adjuvant tamoxifen: Danish Breast Cancer Cooperative Group DBCG 82c randomised trial. Lancet 1999;353:1641-8.

-2 Taghian A, Jeong JH, Mamounas E, Anderson S, Bryant J, Deutsch M, Wolmark N: Patterns of locoregional failure in patients with operable breast cancer treated by mastectomy and adjuvant chemotherapy with or without tamoxifen and adjuvant radiotherapy: results from five National Surgical Adjuvant Breast and Bowel Project randomized clinical trials. J Clin Oncol 2004;22:4247-54.

-3 Early Breast Cancer Trialists Collaborative Group: Effects of radiotherapy and surgery in early breast cancer: an overview of the randomised trials. N Engl J Med 1995;333:1444-55.

4 Mansel RE, Fallowfield L, Kissin M, Goyal A, Newcombe RG, Dixon JM, Yiangou C, Horgan K, Bundred N, Monypenny I, England D, Sibbering M, Abdullah TI, Barr L, Chetty U, Sinnett DH, Fleissig A, Clarke D, Ell PJ: Randomized multicenter trial of sentinel node biopsy versus standard axillary treatment in operable breast cancer: The ALMANAC Trial. J Natl Cancer Inst 2006;98:599609.

5 Olson JA Jr, McCall LM, Beitsch P, Whitworth PW, Reintgen DS, Blumencranz PW, Leitch AM, Saha S, Hunt KK, Giuliano AE: Impact of immediate versus delayed axillary node dissection on surgical outcomes in breast cancer patients with positive sentinel nodes: results from American College of Surgeons Oncology Group Trials Z0010 and Z0011. J Clin Oncol 2008;26:3530-5.
Giuliano AE, Hunt KK, Ballman KV, Beitsch PD, Whitworth PW, Blumencranz PW, Leitch AM, Saha S, McCall LM, Morrow M: Axillary dissection vs. no axillary dissection in women with invasive breast cancer and sentinel node metastasis: a randomized clinical trial. JAMA 2011;305:569-75.

7 Wernicke GA, Goodman RL, Turner BC, Komarnicky LT, Curran WJ, Christos PJ, Khan I, Vandris K, Parashar B, Nori D, Clifford Chao KS: A 10-year follow-up of treatment outcomes in patients with early stage breast cancer and clinically negative axillary nodes treated with tangential breast irradiation following sentinel lymph node dissection or axillary clearance. Breast Cancer Res Treat 2011;125:893-902.

8 Wong JS, Recht A, Beard CJ, Busse PM, Cady B, Chaffey JT, Come S, Fam S, Kaelin C, Lingos TI, Nixon AJ, Shulman LN, Troyan S, Silver B, Harris JR: Treatment outcome after tangential radiation therapy without axillary dissection in patients with early-stage breast cancer and clinically negative axillary nodes. Int J Radiat Oncol Biol Phys 1997;39:915-20.

9 Hoskin PJ, Rajan B, Ebbs S, Tait D, Milan S, Yarnold JR: Selective avoidance of lymphatic radiotherapy in the conservative management of early breast cancer. Radiother Oncol 1992;25:83-8.

10 Halverson KJ, Taylor ME, Perez CA, Garcia DM, Myerson R, Philpott G, Levy J, Simpson JR, Tucker G, Rush C: Regional nodal management and patterns of failure following conservative surgery and radiation therapy for stage I and II breast cancer. Int J Radiat Oncol BioI Phys 1993;26:593-9.

11 Kuznetsova M, Graybill Jc, Zusag TW, Hartsell WF, Griem KL: Omission of axillary lymph node dissection in early-stage breast cancer: effect on treatment outcome. Radiology 1995;197:507-10.
12 Van Wely BJ, Teerenstra S, Schinagl DAX, Aufenacker TJ, de Wilt JHW, Strobbe LJA: Systematic review of the effect of external beam radiation therapy to the breast on axillary recurrence after negative sentinel lymph node biopsy. Br J Surg 2011;98:326-33.

13 Louis-Sylvestre C, Clough K, Asselain B, Vilcoq JR, Salmon RJ, Campana F, Fourquet A: Axillary treatment in conservative management of operable breast cancer: dissection or radiotherapy? Results of a randomized study with 15 years of follow-up. J Clin Oncol 2004;22:97-101.

14 Spruit PH, Siesling S, Elferink MAG, Vonk EJA, Hoekstra C: Regional radiotherapy versus an axillary lymph node dissection after lumpectomy: a safe alternative for an axillary lymph node dissection in a clinically uninvolved axilla in breast cancer. A case control study with 10 years follow up. Radiat Oncol 2007;2:40.

15 Veronesi U, Orecchia R, Zurrida S, Galimberti V, Luini A, Veronesi P, Gatti G, D'Aiuto G, Cataliotti L, Paolucci R, Piccolo P, Massaioli N, Sismondi P, Rulli A, Lo Sardo F, Recalcati A, Terribile D, Acerbi A, Rotmensz N, Maisonneuve P: Avoiding axillary dissection in breast cancer surgery: a randomized trial to assess the role of axillary radiotherapy. Ann Oncol 2005;16:383-8.

16 Wazer DE, Erban JK, Robert NJ, Smith TJ, Marchant DJ, Schmid C, DiPetrillo T, SchmidtUllrich R: Breast conservation in elderly women for clinically negative axillary lymph nodes without axillary dissection. Cancer 1994;74:878-83.

17 Hoebers FJ, Borger JH, Hart AA, Peterse JL, Th EJ, Lebesque JV: Primary axillary radiotherapy as axillary treatment in breast-conserving therapy for patients with breast carcinoma and clinically negative axillary lymph nodes. Cancer 2000;88:1633-42. 
18 Veronesi U, Galimberti V, Paganelli G, Maisonneuve $P$, Viale $G$, Orecchia R, Luini A, Intra M, Veronesi P, Caldarella P, Renne G, Rotmensz N, Sangalli C, De Brito Lima L, Tullii M, Zurrida S: Axillary metastases in breast cancer patients with negative sentinel nodes: a follow-up of 3,548 cases. Eur J Cancer 2009;45:1381-8.

19 Fodor J, Toth J, Major T, Polgar C, Nemeth G: Incidence and time of occurrence of regional recurrence in stage I-II breast cancer: value of adjuvant irradiation. Int J Radiat Oncol Biol Phys 1999;44:281-7.

20 Recht A, Gray R, Davidson NE, Fowble BF, Solin LJ, Cummings FJ, Falkson G, Falkson HC, Taylor SG, Tormey DC: Locoregional failure ten years after mastectomy and adjuvant chemotherapy with or without tamoxifen without irradiation: experience of the Eastern Cooperative Oncology Group. J Clin Oncol 1999;17:1689-700.

-21 Galper S, Recht A, Silver B, Bernardo MVP, Gelman R, Wong J, Schnitt SJ, Connolly JL, Harris JR: Is radiation alone adequate treatment to the axilla for patients with limited axillary surgery? Implications for treatment after a positive sentinal node biopsy. Int J Radiat Oncol Biol Phys 2000;48;125-32.

22 Forrest APM, Everington D, McDonald CC, Steele RJ, Chetty U, Stewart HJ: The Edinburgh randomized trial of axillary sampling or clearance after mastectomy. Br J Surg 1995;82:1504-8.

-23 Tanguay JS, Ford DR, Sadler G, Buckleyz L, Uppaly H, Crossx J, Holmesx N, Fortes Mayery K, Fernando I: Selective axillary node sampling and radiotherapy to the axilla in the management of breast cancer. Clin Oncol (R Coll Radiol) 2008;20:677-82
24 Langer I, Guller U, Viehl CT, Moch H, Wight E, Harder F, Oertli D, Zuber M: Axillary lymph node dissection for sentinel lymph node micrometastases may be safely omitted in early-stage breast cancer patients: long-term outcomes of a prospective study. Ann Surg Oncol 2009;16:3366-74.

25 Guenther JM, Hansen NM, DiFronzo LA, Giuliano AE, Collins JC, Grube BL, O'Connell X: Axillary dissection is not required for all patients with breast cancer and positive sentinel nodes. Arch Surg 2003;138:52-6.

26 Straver ME, Meijnen P, van Tienhoven G, van de Velde CJ, Mansel RE, Bogaerts J, Demonty G, Duez N, Cataliotti L, Klinkenbijl J, Westenberg HA, van der Mijle HA, Hurkmans C, Rutgers EJ: Role of axillary clearance after a tumor-positive sentinel node in the administration of adjuvant therapy in early breast cancer. J Clin Oncol 2010;10:28:731-7.

27 Petrek JA, Heelan MC: Incidence of breast carcinoma-related lymphedema. Cancer 1998;83:277681.

28 Larson D, Weinstein M, Goldberg I, Silver B, Recht A, Cady B, Silen W, Harris JR: Edema of the arm as a function of the extent of axillary surgery in patients with stage I-II carcinoma of the breast treated with primary radiotherapy. Int J Radiat Oncol Biol Phys 1986;12:1575-82.

29 Yeoh EK, Denham JW, Davies SA, Spittle MF: Primary breast cancer. Complications of axillary management. Acta Radiol Oncol 1986;25:105-8.

30 Cabanes PA, Salmon RJ, Vilcoq JR, Durand JC, Fourquet A, Gautier C, Asselain B: Value of axillary dissection in addition to lumpectomy and radiotherapy in early breast cancer. The Breast Carcinoma Collaborative Group of the Institut Curie. Lancet 1992;339:1245-8.
1 Hladiuk M, Huchcroft S, Temple W, Schnurr BE Arm function after axillary dissection for breast cancer: a pilot study to provide parameter estimates. J Surg Oncol 1992;50:47-52.

32 Orecchia R, Huscher A, Leonardi MC, Gennari R, Galimberti V, Garibaldi C, Rondi E, Bianchi LC, Zurrida S, Franzetti S: Irradiation with standard tangential breast fields in patients treated with conservative surgery and sentinel node biopsy: using a three-dimensional tool to evaluate the first level coverage of the axillary nodes. Br J Radiol 2005;78:51-4.

33 Reed DR, Lindsley SK, Mann GN, AustinSeymour M, Korssjoen T, Anderson BO, Moe R: Axillary lymph node dose with tangential breast irradiation. Int $\mathrm{J}$ Radiat Oncol Biol Phys 2005;61:358-64.

34 Dijkema IM, Hofman P, Raaijmakers CP, Lagendijk JJ, Battermann JJ, Hillen B: Locoregional conformal radiotherapy of the breast: delineation of the regional lymph node clinical target volumes in treatment position. Radiother Oncol 2004;71:287-95. 